\title{
Development of a bacterial bioassay for atrazine and cyanuric acid detection
}

\section{OPEN ACCESS}

Edited by:

Elisa Michelini

University of Bologna, Italy

Reviewed by:

Uwe Strotmann,

Westfaelische Hochschule, Germany

Steven Ripp

University of Tennessee, USA

Matti Tapani Karp,

Tampere University of Technology,

Finland

*Correspondence:

Marie-José Durand, IUT Biology, 18 Bd Gaston Defferre,

85035 La Roche-sur-Yon, France marie-jose.durand-thouand@ univ-nantes.fr

Specialty section:

This article was submitted to Microbiotechnology, Ecotoxicology and Bioremediation, a section of the journal Frontiers in Microbiology

Received: 27 January 2015 Accepted: 02 March 2015 Published: 17 March 2015

Citation:

Hua A, Gueuné $H$, Cregut $M$, Thouand

G and Durand M-J (2015)

Development of a bacterial bioassay for atrazine and cyanuric acid detection. Front. Microbiol. 6:211. doi: 10.3389/fmicb.2015.00211

\author{
Anna Hua ${ }^{1}$, Hervé Gueuné ${ }^{1,2}$, Mickaël Cregut ${ }^{1}$, Gérald Thouand ${ }^{1}$ and Marie-José Durand ${ }^{1 *}$ \\ 1 Nantes University, Campus de la Courtaisière - IUT, UMR CNRS 6144 GEPEA, CBAC, La Roche-sur-Yon, France, \\ ${ }^{2}$ CORRODYS, Centre de Corrosion Marine et Biologique, Cherbourg, Octeville, France
}

The s-triazine herbicides are compounds which can disseminate into soils and water. Due to their toxic effects on living organisms, their concentrations in drinking water are legislated by $\mathrm{WHO}$ recommendations. Here we have developed for the first time, to the best of our knowledge, an alternative method for physicochemical quantification using two bioluminescent bacterial biosensors: E. coli SM003 for cyanuric acid detection and E. coli SMOO4 for both atrazine and cyanuric acid detection. The concentration of cyanuric acid detection for $E$. coli SM003 ranges from $7.83 \mu \mathrm{M}$ to $2.89 \mathrm{mM}$, and for $E$. coli SM004 ranges from 0.22 to $15 \mu \mathrm{M}$. Moreover, atrazine detection by $E$. coli SM004 ranges from 1.08 to $15 \mu \mathrm{M}$. According to WHO recommendations, the cyanuric acid detection range is sensitive enough to discriminate between polluted and drinking water. Nevertheless, the detection of atrazine by E. coli SM004 is only applicable for high concentrations of contaminants.

Keywords: bacterial bioelement, bioluminescence, luxCDABE, biodetection, biosensor, atrazine, cyanuric acid, bioassay

\section{Introduction}

The $s$-triazine family herbicide is used for agricultural purposes, such as preventing pre and post-emergence weeds in crops. These herbicides are mobile molecules that disseminate into soils and water. The process leads to the accumulation of a cyanuric acid compound, which is a building block common to the diverse family of $s$-triazine (Ralebitso et al., 2002).

These polluted environments have various toxic effects on all living organisms, from aquatic organisms to animals and human beings. Due to these effects, atrazine use is currently forbidden in most European countries, but still widely used in other parts of the world. According to the WHO, atrazine and cyanuric acid concentrations in drinking water are limited to $2 \mu \mathrm{g} . \mathrm{L}^{-1}(0.01 \mu \mathrm{M})$ and $40 \mathrm{mg} . \mathrm{L}^{-1}(310 \mu \mathrm{M})$, respectively (World Health Organization, 2011).

Monitoring atrazine in environments can be performed by various chemical analyses, including gas chromatography coupled with physico-chemical detection systems. Even if these methods are sensitive, they involve organic extraction of the sample prior to proper analysis, which does not reflect the bioavailable fraction of the contaminant.

In this study, we propose for the first time an alternative method for cyanuric acid and atrazine detection using bacterial biosensors technology. The adopted strategy for construction of the bioelements is uncommon because it integrates, in addition to inducible detection of cyanuric acid, atrazine biodegradation pathway. 
To address this goal, the pADP-1 plasmid, borne by Pseudomonas sp. pADP-1 and well-studied for its ability to degrade atrazine, was used for genetic construction (Mandelbaum et al., 1995) (Figure 1). Atrazine biodegradation pathway is encoded through the atz genes, which can be divided into two sets: $(i)$ the constitutive atzA, atzB, and $a t z C$ genes responsible of atrazine degradation into cyanuric acid and (ii) the inducible atzDEF operon, leading to cyanuric acid mineralization into $\mathrm{NH}_{3}$ and $\mathrm{CO}_{2}$. Moreover, the atzDEF expression requires the constitutive expression of its regulator atzR (Govantes et al., 2010).

Since atrazine degradation genes into cyanuric acid are constitutively expressed, their promoters cannot be used as bioreporters. Therefore, atrazine biodetection can be developed solely after its initial biodegradation into cyanuric acid. In these conditions, we developed a two-step strategy consisting in developing two complementary strains: one for cyanuric acid detection only and the second for atrazine biodetection after its biodegradation into cyanuric acid (Figure 1).

\section{Materials and Methods}

\section{Bacterial Strains, Media, and Growth Conditions}

Bacterial strains (Table 1) were grown in Terrific Broth (TB) medium (Sigma-Aldrich, Fr) at $37^{\circ} \mathrm{C}$ in the presence of ampicillin (100 mg.L $\mathrm{L}^{-1}$, Sigma-Aldrich, Fr) and gentamicin $\left(25 \mathrm{mg} . \mathrm{L}^{-1}\right.$, Sigma-Aldrich, Fr), and agitated at $250 \mathrm{rpm}$ in baffled shack flasks.

\section{Pollutant Solutions}

Stock solutions of cyanuric acid and atrazine (both from SigmaAldrich, Fr, purity $\geq 98 \%$ ) were made in isopropanol/ultrapure water $(20 / 80 \mathrm{v} / \mathrm{v})$ at concentrations of $2.5 \mathrm{mM}$ and $150 \mu \mathrm{M}$, respectively. These solutions were stocked at $-20^{\circ} \mathrm{C}$ for 3 months and diluted in ultrapure water to required concentrations prior to use. Because solubility thresholds differ from cyanuric acid and atrazine $(21 \mathrm{mM}$ and $161 \mu \mathrm{M}$, respectively), the concentration ranges used for exposure were

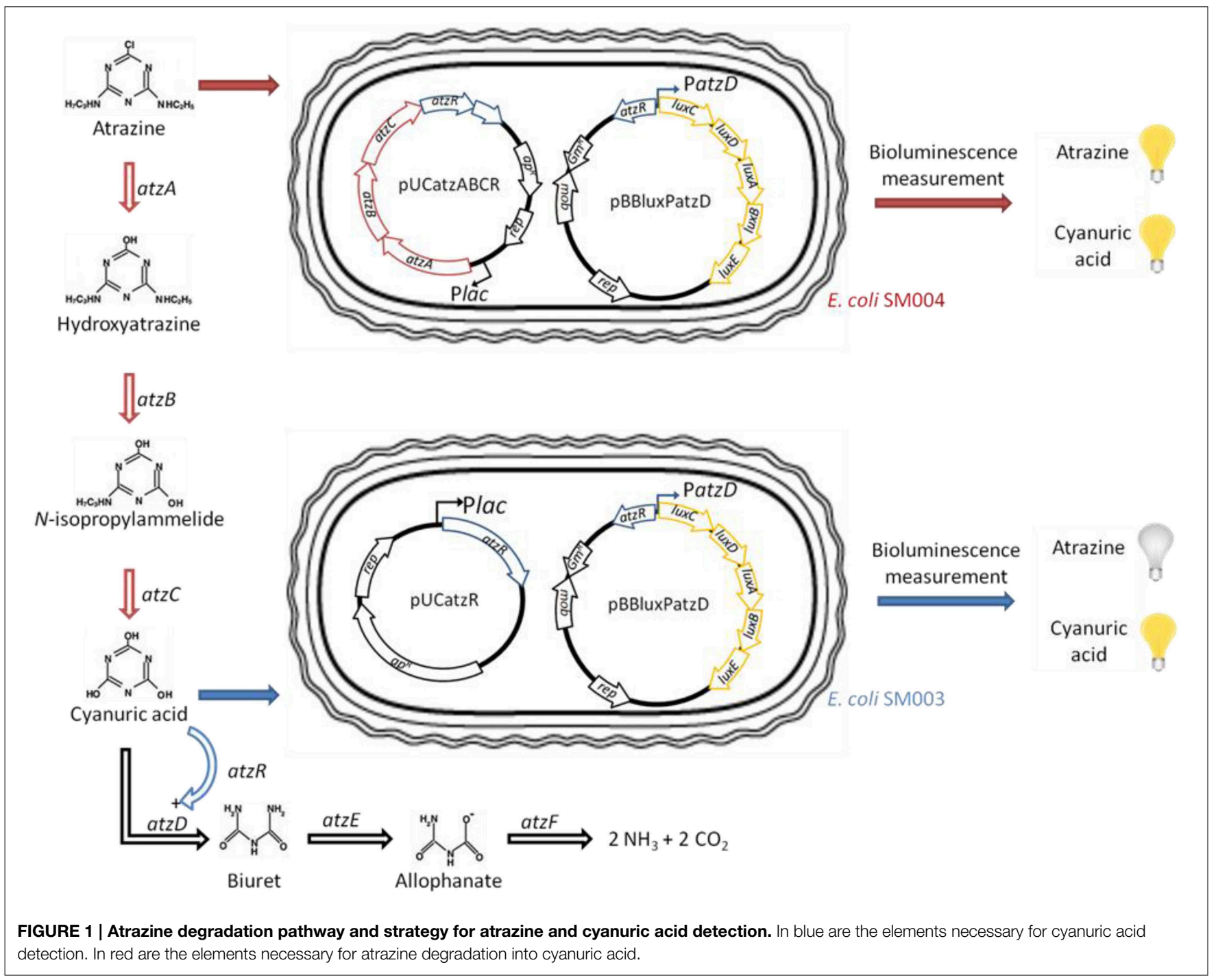


TABLE 1 | Bacterial strains and plasmids used for biosensor construction.

\begin{tabular}{|c|c|c|}
\hline Name & Description & References \\
\hline \multicolumn{3}{|l|}{ BACTERIAL STRAINS } \\
\hline E. coli JM109 & $\begin{array}{l}\text { endA1 glnV44 thi-1 relA1 gyrA96 recA1 mcrB+ } \Delta(l a c-p r o A B) \text { e14- }\left[F^{\prime} \text { traD36 proAB+laclq }\right. \\
\text { lacZ } \Delta M 15] \text { hsdR17(rK-mK+) }\end{array}$ & Sigma-Aldrich \\
\hline Pseudomonas sp. ADP & $\mathrm{pADP}-1, \mathrm{Hg}$ & Mandelbaum et al., 1995 \\
\hline E. coli SM003 & E. coli JM109, pBBluxatzD, pUCatzR, $\mathrm{Ap}^{\mathrm{R}}, \mathrm{Gm}^{\mathrm{R}}$ & This study \\
\hline E. coli SM004 & E. coli JM109, pBBluxatzD, pUCatzABCR, Ap ${ }^{R}, \mathrm{Gm}^{\mathrm{R}}$ & This study \\
\hline \multicolumn{3}{|l|}{ PLASMIDS } \\
\hline pBfiluxCDABE & $\begin{array}{l}A p^{R}, p t a c:: l u x C D A B E, \text { constitutive expression of the Aliivibrio fischeri bioluminescence } \\
\text { luxCDABE operon }\end{array}$ & Charrier et al., 2011 \\
\hline pBfiluxMCS & $A p^{R}, p B f i l u x C D A B E$ containing MCS and $l u x C D A B E$ operon & This study \\
\hline pBBR1MCS-5 & $\mathrm{Gm}^{\mathrm{R}}$, cloning vector rep, lacZ' & NCCB 3437 \\
\hline pBBluxMCS & $\mathrm{Gm}^{\mathrm{R}} \mathrm{pBBR} 1 \mathrm{MCS}-5$ containing MCS and luxCDABE operon & This study \\
\hline pBBluxPatzD & $\mathrm{Gm}^{R}$ pBBluxMCS containing atzR and PatzDEF promoter & This study \\
\hline pUC19 & $A p^{R}$, high copy number cloning vector & Invitrogen \\
\hline pUCatzR & $A p^{R}$ pUC19 containing atzR gene & This study \\
\hline pUCatzABC & $A p^{R}$ pUC19 containing atz $A$, atzB et atz $C$ genes & This study \\
\hline pUCatzABCR & $A p^{R}$ pUCatzR containing atz $A$, atzB et atz $C$ genes & This study \\
\hline
\end{tabular}

between $4 \mathrm{nM}$ and $4 \mathrm{mM}$ and between $8 \mathrm{nM}$ and $15 \mu \mathrm{M}$, respectively.

\section{Molecular Biology for Reporter Plasmid Construction}

In this study, we aimed to develop a set of two complementary strains reporting cyanuric acid and atrazine. The strategy employed was based on the use of the molecular resources of the pADP1 plasmid, bearing the genes encoding for $(i)$ the biodegradation of atrazine into cyanuric acid, encoded by the atzA, atzB, and $a t z C$ genes; and (ii) cyanuric acid biosensing achieved by the $a t z D$ promoter and its regulator atzR. $\operatorname{Lux} C D A B E$ reporter genes were used from Allivibrio fischeri (Supplementary Data).

Once constructed, E. coli JM109 cells (Sigma-Aldrich, Fr) were transformed by pBBluxPatzD and pUCatzR for E. coli SM003 and pBBluxPatzD and pUCatzABCR for E. coli SM004 (Charrier et al., 2011). Those transformations lead to the bioelements for $(i)$ cyanuric acid and (ii) both atrazine and cyanuric acid biodetection, respectively (Table 1).

\section{Bioluminescence Measurement and Statistical Analysis}

After overnight growth at $37^{\circ} \mathrm{C}$ in $\mathrm{TB}$ medium agitated at $250 \mathrm{rpm}$, microbial cells were diluted to an absorbance $\left(\mathrm{A}_{620}\right)$ of 0.2 and cultivated at $30^{\circ} \mathrm{C}$ to promote luciferase protein expression. When biomass reached $\mathrm{A}_{620}=0.7$, IPTG induction $(2 \mathrm{mM})$ was performed to induce AtzABCR biosynthesis. After an average of three bacterial generations (around $\mathrm{A}_{620}=1.7$ ), bacterial culture was diluted at $\mathrm{A}_{620}=0.25$ in $1 / 10 \mathrm{~TB}$ medium without antibiotics, to obtain $2 \mathrm{~mL}$ of bacterial suspension. The latter was then induced with various amounts of pollutants (cyanuric acid or atrazine) and shaken in a 24 -well microplate for five minutes to enable the homogenization of the chemical in the media. Finally, $200 \mu \mathrm{L}$ of the bacterial suspension was transferred into a white 96-well microplate for bioluminescence measurement. Bioluminescence was recorded over $4 \mathrm{~h}$ with an acquisition time of 1 second per well at $30^{\circ} \mathrm{C}$ using a luminometer (Berthold, Fr).

Raw bioluminescence results were represented as Relative Luminescence Units per second (RLU.s ${ }^{-1}$ ). The Induction Ratio (IR) was calculated as follows: IR $=\left(\text { RLU. }{ }^{-1}\right)_{\mathrm{I}} /\left(\mathrm{RLU}_{\mathrm{s}} \mathrm{s}^{-1}\right)_{0}$, where (RLU.s $\left.{ }^{-1}\right)_{\mathrm{I}}$ is bioluminescence after exposure with the pollutant, and (RLU.s $\left.{ }^{-1}\right)_{0}$ is the bioluminescence of the bacterium in the absence of pollutant.

Statistical analyses were performed with GraphPad Prism software. Because of the many dose-response curves fit to a sigmoid, the logistic curve $\log$ (substance) vs. response model was applied. This model allows for the calculation of the bioluminescence value $\mathrm{Y}$ in presence of the pollutant at the concentration $\mathrm{X}$. This equation takes into account four parameters: $(i)$ the saturation signal corresponding to the maximum IR value; (ii) the background signal corresponding to the minimum IR value; (iii) the $\log \left(\mathrm{IR}_{50}\right)$ that provokes a response halfway between saturation and background signals and (iv) the Hill slope describing how steep the curve is. The modeled curve is defined as follows:

$$
\begin{aligned}
\text { Bioluminescence } \mathrm{Y}= & \begin{array}{l}
\text { Background }+ \\
(\text { Saturation }- \text { Background })
\end{array} \\
& \frac{10^{[(\log (\operatorname{IR} 50)-\log (\mathrm{X})] \times \text { Hill slope }}}{1+{ }^{2}}
\end{aligned}
$$

Moreover, the following equation allows for the calculation of detection and saturation limits, with $F=10$ and $F=90$, respectively.

$$
\log \left(\mathrm{IR}_{\mathrm{F}}\right)=\log \mathrm{IR}_{50}+\frac{1}{\text { Hill slope } \mathrm{x} \log \left(\frac{\mathrm{F}}{100-\mathrm{F}}\right)}
$$




\section{Results and Discussion}

\section{Cyanuric Acid Biodetection by E. Coli SM003 and E. Coli SM004}

E. coli SM003 strain was assessed for cyanuric acid biodetection. In the absence of the pollutant, luxCDABE genes expression were low and a basal bioluminescence was measured (approximately 70 RLU. ${ }^{-1}$ ). In the presence of increasing concentrations of cyanuric acid, bioluminescence increased (Figure 2A). Thus, in the range of tested concentrations of cyanuric acid, bacterial response was concentration-dependent, demonstrating that the E. coli SM003 strain can be used as a cyanuric acid bioreporter, with a detection limit of $7.82 \mu \mathrm{M}$.

Bioluminescence levels varied over time, increasing until a maximum and then slightly decreasing. This can be explained by the metabolic limitations of the bacterium, which possesses a defined luciferase substrate turnover and so, a limited ability to cope with a defined amount of pollutants. Moreover, background bioluminescence depended on the experiment $(68 \pm 26$ RLU. ${ }^{-1}$ for E. coli SM003 in three replicates). Thus, bioluminescence variations intra- and inter-experimentally can be explained by differences in bacterial physiological states.

To take into account bioluminescence level variations, the time after exposure for IR calculation was fixed. Based on the higher value of the population variance, which reflects the broader spread of bioluminescence values at a given time, the optimal time for bioluminescence analysis was set at $2 \mathrm{~h} 30 \mathrm{~min}$ after cyanuric acid exposure.

A predictive model was established to represent bacterial bioluminescence as a function of pollutant concentrations. The $\mathrm{r}^{2}$ value of the fitted curve was approximately 0.96 , indicating that the applied model was valid (Table 2). The modeled sigmoid presented a bottom and a top plateau (Figure 2B), which can be defined as detection and saturation thresholds. By establishing them as $I_{10}$ and $I R_{90}$, respectively, cyanuric acid detection by

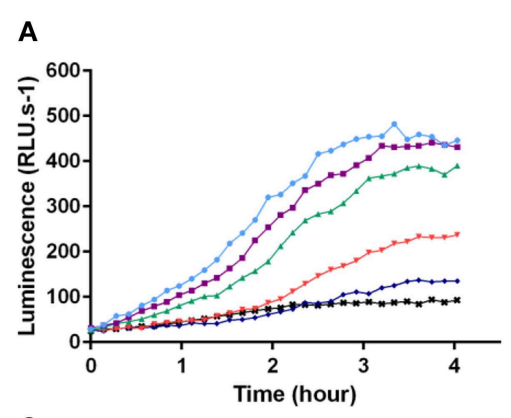

C

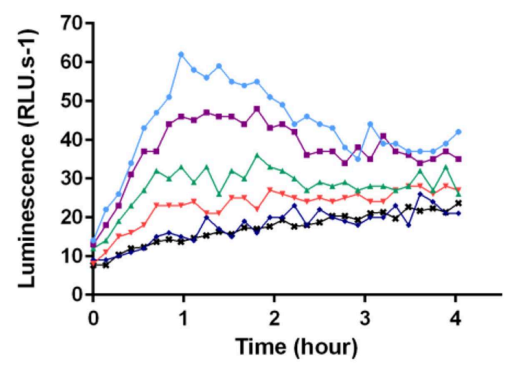

E

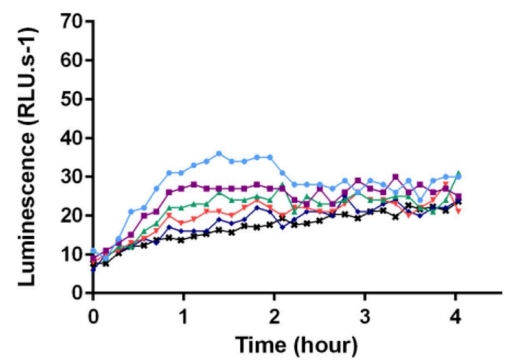

$\rightarrow 2.00 \mathrm{mM}$

$\rightarrow 0.50 \mathrm{mM}$

$+0.13 \mathrm{mM}$

$\rightarrow 0.03 \mathrm{mM}$

- $0.01 \mathrm{mM}$

* Negative control

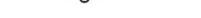

- $1.55 \mathrm{mM}$

$\rightarrow 0.39 \mathrm{mM}$

$\rightarrow 0.10 \mathrm{mM}$

$\rightarrow 0.05 \mathrm{mM}$

- $0.01 \mathrm{mM}$

$\rightarrow$ Negative control

- $0.02 \mathrm{mM}$

$\rightarrow 0.01 \mathrm{mM}$

$\rightarrow 0.004 \mathrm{mM}$

$\rightarrow 0.002 \mathrm{mM}$

- $0.001 \mathrm{mM}$

$\rightarrow$ Negative control

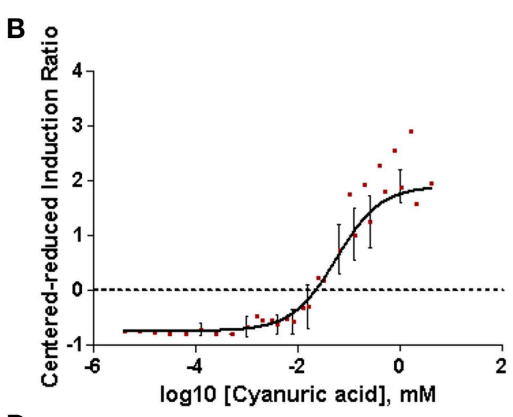

D

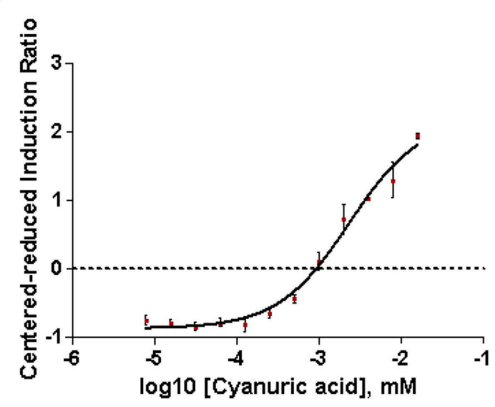

F

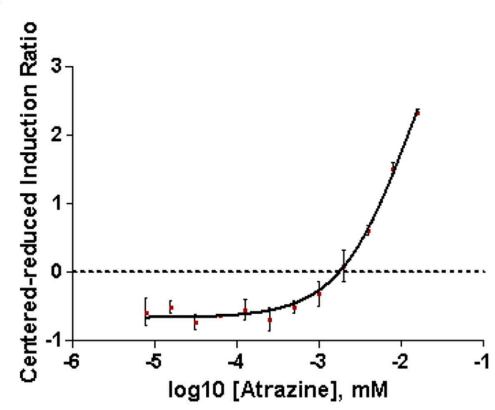

FIGURE 2 | Example of the kinetic of bacterial bioluminescence production. E. coli SM003 strain in the presence of cyanuric acid (A), E. coli SM004 strain in the presence of cyanuric acid (C) or atrazine (E). Modeled curves of centered-reduced induction ratio for $\mathrm{E}$. coli $\mathrm{SMOO3}$ at an exposure time of $2 \mathrm{~h} 30 \mathrm{~min}$ in the presence of cyanuric acid (B), and E. coli SM004 at an exposure time of $1 \mathrm{~h}$ in the presence of cyanuric acid (D) or atrazine (F). Bioluminescence measurements and induction ratio are calculated from duplicate of three independent experiments. 
TABLE 2 | Modeled curve parameters.

\begin{tabular}{|c|c|c|c|c|c|}
\hline Pollutant & Bacterial strain & Modeled curve equation & $r^{2}$ & Detection limit & Saturation limit \\
\hline \multirow[t]{2}{*}{ Cyanuric acid } & E. coli SM003 & $Y=-0.7117+\frac{(2.027+0.7117)}{1+10^{[(-1.325-\log (X)] \times 1.341}}$ & 0.9577 & $7.83 \mu \mathrm{M}$ & $2.89 \mathrm{mM}$ \\
\hline & E. coli SMOO4 & $Y=-0.8613+\frac{(2.101+0.8613)}{1+10[-2.672-\log (X)] \times 1.070}$ & 0.9871 & $0.22 \mu \mathrm{M}$ & $15 \mu \mathrm{M}$ \\
\hline Atrazine & E. coli SM004 & $Y=-0.6333+\frac{(3.508+0.6333)}{1+10^{[-2.128-\log (X)] \times 1.252}}$ & 0.9952 & $1.08 \mu \mathrm{M}$ & $15 \mu \mathrm{M}$ \\
\hline
\end{tabular}

The modeled curve equation is based upon the equation described in the Materials and Methods section. The detection and saturation limits are defined as log(IR $\left.{ }_{10}\right)$ and log(IRgo), respectively.

the E. coli SM003 biosensor ranges between $7.83 \mu \mathrm{M}$ to $2.89 \mathrm{mM}$. The range of detected concentrations is wide enough to discriminate between drinking and polluted water according to WHO recommendations $(310 \mu \mathrm{M}$ of cyanuric acid in drinking water). This range can also be able to detect significant pollution because cyanuric acid solubility is defined as 2.7 g.L $\mathrm{L}^{-1}(21 \mathrm{mM})$, proving that all the substance is bioavailable.

Upon cyanuric acid exposure, E. coli SM004 bioluminescence levels increased with the presence of increased amounts of pollutant in a dose-dependent manner. Based on the population variance study, the optimal bioluminescence analysis time was set as $1 \mathrm{~h}$ after pollutant exposure (Figure 2C). The applied model (Figure 2D and Table 2) defined the detected range of cyanuric acid as ranging from 0.22 to $15 \mu \mathrm{M}$. Thus, the range of detected concentrations of cyanuric acid is sensitive enough to discriminate between drinking and polluted water according to $\mathrm{WHO}$ recommendations.

Even when E. coli SM003 and E. coli SM004 bioelements were both designed for cyanuric acid detection, differences were shown. In comparison with E. coli SM003, the E. coli SM004 growth rate is reduced $\left(0.82\right.$ vs. $0.49 \mathrm{~h}^{-1}$ in $\mathrm{TB}$ medium at $30^{\circ} \mathrm{C}$ ), bioluminescence levels are lower and the cyanuric detection range is lower. These phenomena could be explained by the presence of the three $a t z A$, atzB, and $a t z C$ supplemental genes in the $E$. coli SM004 bioelement, which increases energy requirements. It could be supposed that E. coli SM004 has less energy to cope with the pollutant so, small amounts of pollutant will have larger effects and lead to more sensitive detection with a lower range.

\section{Atrazine Biodetection by E. coli SM004}

E. coli SM004 bioluminescence production in the presence of atrazine was concentration-dependent (Figure 2E). Based on the modeled sigmoidal curve, detectable atrazine concentrations were comprised between 1.08 and $15 \mu \mathrm{M}$ (Figure $2 \mathrm{~F}$ and Table 2). The detection limit is not as low as required to detect non-drinkable water, but is sufficient to detect high levels of atrazine contamination if atrazine solubility is defined at 34.7 mg.L ${ }^{-1}(161 \mu \mathrm{M})$.

In E. coli SM004, the less sensitive detection of atrazine in comparison with cyanuric acid can be explained by the presence of the three supplemental genes. They imply the launching of an enzymatic machinery to achieve the production of cyanuric acid before its bioreporting by another enzymatic system, which also requires more energy. More generally, this biosensor is limited by the ability to manage the presence of atrazine degradation genes and their related metabolic load.

Moreover, it was shown that in the presence of different concentrations of atrazine the bioluminescence produced by E. coli SM003 was not different from the background value (data not shown).

\section{Conclusion}

Many bioluminescent engineered bacteria have been reported in the literature, most of them dedicated to metals detection (Sorensen et al., 2006; Magrisso et al., 2008; Van der Meer and Belkin, 2010; Eltzov and Marks, 2011, for review). Xu et al. (2014) recently reviewed whole-cell bioluminescent bioassay for organic compounds detection, nevertheless none of them are dedicated to triazine.

In this study, we constructed two bacterial bioelements for pollution assessment by the $s$-triazine family compound: one for cyanuric acid, and one for both cyanuric acid and atrazine detection. In vitro studies have shown that, individually, those bioelements are able to detect and quantify pollutants by luminescence measurement.

With environmental samples, the detection of pollutants and discrimination between atrazine or cyanuric acid compounds can be performed by coupling the two bioelements. Because the cyanuric acid detection range differs from E. coli SM003 and E. coli SM004, the detection range of multiple biosensors corresponds to the detection range of the more sensitive strain, i.e., E. coli SM004 $(0.22-15 \mu \mathrm{M})$. This strain is sensitive enough to discriminate cyanuric acid pollution in drinking water, according to WHO recommendations, which limits its concentration at $310 \mu \mathrm{M}$.

Atrazine detection limit by E. coli SM004 bioelement starts from $1 \mu \mathrm{M}$, which allows the detection of large atrazine contaminations only. Non-sensitive detection of atrazine by the E. coli SM004 bioelement can be explained by its large energy requirements, due to the presence of the supplemental genes responsible for atrazine degradation into cyanuric acid. Despite the fact that atrazine detection remains to be improved, $s$ triazine family contaminations can easily be detected by the sole detection of cyanuric acid. Indeed, because cyanuric acid is produced following the degradation of the $s$-triazine 
family, its quantification by the E. coli SM004 bioelement is sufficient to discriminate between polluted and drinking water.

Further studies can be conducted to decrease detection limits. It would be interesting to enhance bioluminescence levels by the addition of luciferase cofactors, such as riboflavin. Moreover, an integration of the constitutively expressed atz$A B C R$ genes into the bacterial genome would reduce the metabolic load due to plasmid replication, remove an antibiotic resistance gene and, finally, simplify the induction protocol without the IPTG addition step. Once these optimization steps are conducted, the biosensors will be validated for cyanuric acid and atrazine detection first on mixtures with different proportions, and then in environmental and complex samples.

\section{References}

Charrier, T., Durand, M. J., Jouanneau, S., Dion, M., Pernetti, M., Poncelet, D., et al. (2011). A multi-channel bioluminescent bacterial biosensor for the on-line detection of metals and toxicity. Part I: design and optimization of bioluminescent bacterial strains. Anal. Bioanal. Chem. 400, 1051-1060. doi: 10.1007/s00216-010-4353-9

Eltzov, E., and Marks, R. S. (2011). Whole- cell aquatic biosensors. Anal. Bioanal. Chem. 400. 895-913. doi: 10.1007/s00216-0104084-y

Govantes, F., García-González, V., Porrúa, O., Platero, A. I., Jiménez-Fernández, A., and Santero, E. (2010). Regulation of the atrazine-degradative genes in Pseudomonas sp. strain ADP. FEMS Microbiol. Lett. 310, 1-8. doi: 10.1111/j.15746968.2010.01991.x

Magrisso, S., Erel, Y., and Belkin, S. (2008). Microbial reporters of metal bioavailability. Microb. Biotechnol. 1, 320-330. doi: 10.1111/j.1751-7915.2008. 00022.x

Mandelbaum, R. T., Allan, D. L., and Wackett, L. P. (1995). Isolation and characterization of a Pseudomonas sp. that mineralizes the s-triazine herbicide atrazine. Appl. Environ. Microbiol. 61, 1451-1457.

Ralebitso, T. K., Senior, E., and Van-Verseveld, H. W. (2002). Microbial aspects of atrazine degradation in natural environments. Biodegradation 13, 11-19. doi: 10.1023/A:1016329628618

\section{Acknowledgments}

We thank Fernando Govantes's laboratory (Fernando Govantes Centro Andaluz de Biología del Desarrollo, Universidad Pablo de Olavide/Consejo Superior de Investigaciones Científicas/Junta de Andalucía, Sevilla, Spain) for giving the Pseudomonas sp. ADP bacterial strain. The authors thank their financial support (Ville de la Roche sur Yon, Conseil Général de Vendée, conseil régional des Pays de la Loire and the French Ministry of Research).

\section{Supplementary Material}

The Supplementary Material for this article can be found online at: http://www.frontiersin.org/journal/10.3389/fmicb. 2015.00211/abstract

Sorensen, S. J., Burmolle, M., and Hansen, L. H. (2006). Making bio-sense toxicity: new developments in whole- cells biosensors. Curr. Opin. Biotechnol. 17, 11-16. doi: 10.1016/j.copbio.2005.12.007

Van der Meer, J. R., and Belkin, S. (2010). Where microbiology meets microengineering: design and application of reporter bacteria. Nat. Rev. Microbiol. 8, 511-522. doi: 10.1038/nrmicro2392

World Health Organization. (2011). Guidelines for Drinking-water Quality, 4th Edn. Geneva: World Health Organization

$\mathrm{Xu}$, T., Close, D., Smartt, A., Ripp, S., and Sayler, G. (2014). "Detection of organic compounds with whole-cell bioluminescent bioassays," in Bilouminescence: Fundamentals and Applications in Biotechnogy, Vol. 1, eds G. Thouand and R. Marks (Berlin; Heidelberg: Advances in Biochemical Engineering/Biotechnology v 144, Series Editors T. Scheper., Springer), 111-151.

Conflict of Interest Statement: The authors declare that the research was conducted in the absence of any commercial or financial relationships that could be construed as a potential conflict of interest.

Copyright (c) 2015 Hua, Gueuné, Cregut, Thouand and Durand. This is an openaccess article distributed under the terms of the Creative Commons Attribution License (CC BY). The use, distribution or reproduction in other forums is permitted, provided the original author(s) or licensor are credited and that the original publication in this journal is cited, in accordance with accepted academic practice. No use, distribution or reproduction is permitted which does not comply with these terms. 